\title{
Reactivity Initiated Transient Response of TRIGA with the Progress of Core Burnt
}

\author{
F. Haque ${ }^{1}$ and N.H. Badrun ${ }^{2^{\star}}$ \\ ${ }^{I}$ Military Institute of Science and Technology, Mirpur Cantonment, Dhaka-1216, Bangladesh. \\ ${ }^{2}$ Reactor Physics and Engineering Division, INST, AERE, Ganakbari, Savar, Dhaka-1349, Bangladesh.
}

\section{ARTICLE INFO}

\section{Article history:}

Received 7 October 2019

Received in revised form 7 July 2020

Accepted 20 July 2020

\section{Keywords:}

EUREKA-2/RR

COOLOD-N2

TRIGA core

Burnt

Reactivity

Insertion duration

\begin{abstract}
A B S T R A C T
This paper illustrates the effects on safety of TRIGA Mark-II research reactor of Bangladesh at its different steps of core burnt during reactivity induced transient. The modeling and simulation were carried by coupled point kinetics, neutronics, and thermal hydraulics code EUREKA-2/RR based on neutronics data calculated previously by Monte Carlo code for different burnt states of TRIGA core. Three burn steps until 150 MWD have been considered for present analysis which are regarded here as beginning of cycle (BOC); middle of cycle, MOC (75 MWD); and end of cycle, EOC (150 MWD). Initially, the results of steady state analysis obtained from EUREKA code for these three burn steps have been verified with that of COOLOD code. Based on consistency of the results from the two codes, transient simulation has been conducted considering reactor with non-function of scram. Reactivity inserted amount ranges within 0.001 to $0.02 \mathrm{dk} / \mathrm{k}$ with three durations of insertions of $0.1 \mathrm{~s}, 1 \mathrm{~s}$, and $5 \mathrm{~s}$. Major parameters such as reactor core maximum power and fuel clad maximum temperature have been reported. The analysis presents transient pattern of these parameters due to change in amount and duration of inserted reactivity. The maximum imposed reactivity that causes the fuel clad to exceed its design temperature at each burn step has been evaluated in this study. It is also observed here for each amount and durations of inserted reactivity, maximum value of both power and clad temperature found to decrease with the progress of core burnt. These results obtained from this analysis will be useful for reactor operators and management team during core upgrading and modification program.
\end{abstract}

(C) 2020 Atom Indonesia. All rights reserved

\section{INTRODUCTION}

The 3-MW TRIGA Mark-II research reactor (BTRR) is the only reactor of Bangladesh and has been in operation over the last 27 years. Since its commissioning in 1986, the reactor has been engaged in production of radioisotopes for uses in agriculture, industry, and medicine all over the country as well as in conducting research and manpower training in various fields of nuclear science. To make the most effective use of reactor with the extension of its core life time, efforts have been paid in improving its in-core fuel management by the calculation of different neutronics parameters including individual fuel burnup at different cycles of reactor operation. Contribution of Huda et al. [1],

*Corresponding author.

E-mail address: nhbadrun@yahoo.com

DOI: https://doi.org/10.17146/aij.2020.983
Rahman et al. [2], Mahmood et al. [3], and M. Assaduzzaman [4] can be referred in this regard. In fact, for every modification of reactor core, thermal hydraulic safety against normal and accidental conditions needs to be ensured prior to its utilization. In order to perform research reactor safety calculations, two broad categories of design basis accidents are usually considered. These are namely, reactivity initiated accident (RIA) and loss of flow accident (LOFA). It is also customary to consider systematically transient with and without scram availability (self-limited transients) [5]. If reactor scram system available, the clad temperature usually could remain well below the clad melting temperature. But, in self-limited transient, all the trips to control the reactor become non-functional, so the net reactivity becomes completely dependent on the initiating external reactivity and the feedback reactivity mechanism 
inherent in the reactor. Even if the inserted reactivity is sufficiently large that could not be compensated by reactor feedback reactivity, the reactor at that situation could not be treated protected because it could lead core damage with release of fission products [6]. Hence, limit of inserted reactivity for unprotected transient is important to report from safety as well as operation point of view.

Reactivity initiated transient analysis of TRIGA reactor is certainly not new although most of these works reported so far in the context of analysis fresh core [6-8]. But, in order to strengthening safety analysis, transient study with the progress of core burnt of unprotected TRIGA needs to be addressed which have not been conducted for TRIGA until to date. So, reactor operators may overlook reactor data on safety parameters for unprotected TRIGA core with its core burnt status. Hence, based on neutronics of TRIGA burnt core [1-3], the aim of present work is then of three fold; firstly, to report the pattern of core power and clad temperature for each reactivity imposed with each duration at each burn step; secondly, to evaluate the inserted maximum reactivity for which there will be obtained no fuel clad failure at different core burnt steps; and thirdly, to report for each amount and duration of inserted reactivity, how the maximum values of core power and clad temperature vary with the progress of core burnt. Coupled point kinetics, neutronics, and thermal hydraulics code EUREKA-2/RR has been used for this purpose.

\section{OVERVIEW OF NEUTRONIC STUDIES FOR TRIGA CORE}

There is a link between neutronic and thermal hydraulic analysis of a reactor core since heat energy generated in the core is induced by the fission neutrons. This paper considers reports of Huda et al. [1], Rahman et al., [2], and Mahmood et al. [3] from which individual fuel element burnup together with power peaking factors calculations have been found carried so far for 700 MWD burnt core of TRIGA. These previous calculations were mostly conducted using three-dimensional continuous energy Monte Carlo code MVP considering cross section data library JENDL3.3. If the power peaking factors values of each fuel element at different burnup states are considered, it is found that $\mathrm{C} 4$ fuel element remains the hottest until 200 MWD but onward from it, C10 becomes the hottest until 700 MWD burnt [9]. Hence, which one will be the hottest fuel rod in the reactor depends on the progress of its core burnt. Figure 1 presents the locations of $\mathrm{C} 4$ and $\mathrm{C} 10$ fuel elements in the TRIGA core [10]. For brevity, the present simulation considers core burnt only until 150 MWD which can be considered in terms of three states such as beginning of cycle (BOC); middle of cycle, MOC (75 MWD); and end of cycle, EOC (150 MWD). Table 1 provides peaking factors of fuel rod $\mathrm{C} 4$ at these three steps which were used in steady state thermal hydraulic analysis prior to transient simulation employed in EUREKA code [9].

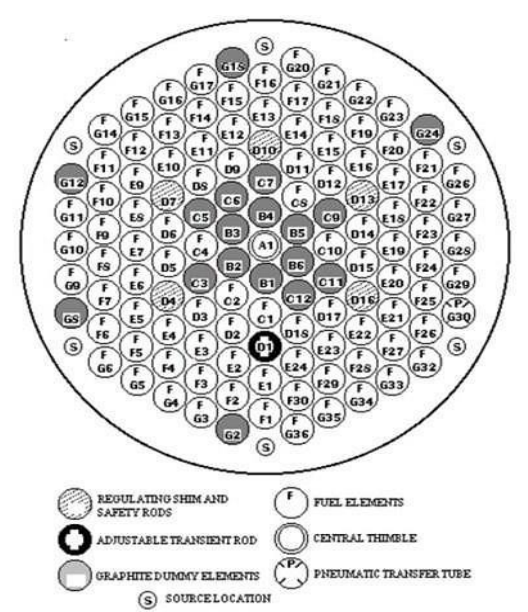

Fig. 1. Configuration of 3 MW TRIGA Mark-II Research Reactor.

Table 1. Peaking factors of $\mathrm{C} 4$ at three steps of burnup.

\begin{tabular}{llll}
\hline Peaking Factors & \multicolumn{3}{c}{ C4 } \\
\hline Radial Peaking & BOC & MOC & EOC \\
Axial Peaking actor & 1.668 & 1.660 & 1.651 \\
Total Peaking Factor & 1.218 & 1.222 & 1.225 \\
\hline
\end{tabular}

\section{TRANSIENT SIMULATION}

Before transient simulation, readers are encouraged to go through an earlier report, referred as [9], which is particularly on steady state thermal hydraulic modeling and analyses for three different states of TRIGA core burnt using EUREKA code. Although EUREKA-2/RR is proven as a trusted code, however, the code has been verified by comparing its prediction from another well-known thermal hydraulic code, COOLOD-N2 [11] before proceed with the present transient analysis. Fuel, cladding and coolant temperature values obtained from EUREKA code at steady state condition have been compared against the calculations of COOLOD-N2 code for same rated thermal power of 3 MW of TRIGA. All the analytical results are provided in Table 2 which illustrate that calculation of EUREKA-2/RR agrees pretty well with the results of COOLOD-N2. Considering this agreement, model developed for TRIGA core with 
three burnt states have been used for present transient simulation in EUREKA code.

Among postulated reactivity accidents drop of a fuel element on the core at start up or at different operational power of the reactor, flooding of beam tube, failure of heavy water tank, increase of primary coolant flow rate (cold water insertion), removal of in-pile experiments; the clad temperature attains maximum value in the case of removal of inpile experiments. From this point of view, removal of in-pile experiment has been chosen for the present study. The reactivity considered for the simulation ranges between less than $0.007 \mathrm{dk} / \mathrm{k}(1 \$)$ to more than $0.014 \mathrm{dk} / \mathrm{k}(2 \$)$ which are $0.001,0.003,0.005$, $0.007,0.009,0.10,0.012,0.014,0.016,0.018$ and $0.020 \mathrm{dk} / \mathrm{k}$. The duration of each inserted reactivity varied by $0.1 \mathrm{~s}, 1 \mathrm{~s}$ and $5 \mathrm{~s}$. Reactor was in full power operation with forced convection cooling mode. The total simulation time was considered 80s. The analysis is considered unprotected as a result of non-function of scram. In defining simulation unprotected, the delay time to attain reactor at its trip power of $3.3 \mathrm{MW}$ was taken $70 \mathrm{~s}$. This allows reactor not to be shut down until duration of $70 \mathrm{~s}$. It reveals that reactor will remain unprotected until 70s. During this situation, transient behavior of two major parameters such as reactor core power and peak clad temperature of the hottest fuel rod have been studied.

\section{RESULTS AND DISCUSSION}

Transient studies due to externally inserted reactivity are discussed below:

\section{Transient of reactor core power}

For each step of core burnt, for all ranges of inserted reactivity with three different durations of insertions $0.1 \mathrm{~s}, 1 \mathrm{~s}$ and $5 \mathrm{~s}$; if time behavior of reactor core power is plotted, it has been observed that although reactor core power increases with the increase in reactivity; but the power profiles follow different patterns with different amount and durations of insertion reactivity. If focus given on these patterns, it is seen for $0.1 \mathrm{~s}$ duration of insertion, although the peak power increases to a level of several hundred times of steady state power level, the power returns immediately to the normal operating range. This is due to prompt negative temperature coefficient of reactivity which is a unique feature of TRIGA. For $1 \mathrm{~s}$ insertion, this power increase is relatively slower with having a peak at $1 \mathrm{~s}$ until $0.014 \mathrm{dk} / \mathrm{k}$ reactivity, but beyond this reactivity, a preliminary peak appears before achieving the single peak at $1 \mathrm{~s}$. The kind of oscillations observed at this extent of reactivity is due to competition in positive and negative reactivity. This negative reactivity is a result of doppler feedback reactivity whose contribution for TRIGA is relatively more significant than void/density coefficient and coolant temperature coefficient of reactivity [10]. For insertion duration $5 \mathrm{~s}$, the profile shows a single peak at $5 \mathrm{~s}$ for all ranges of reactivity at all three burnt states. Figure 2 shows transient profiles of power for different durations of insertion for MOC.

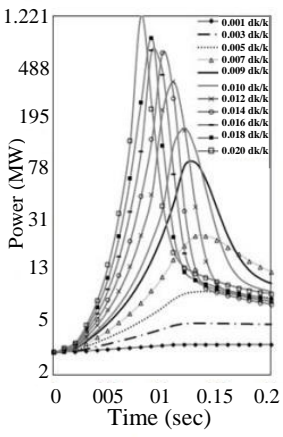

(a)

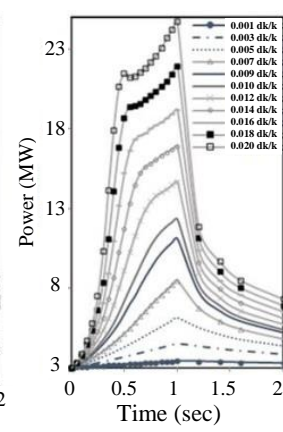

(b)

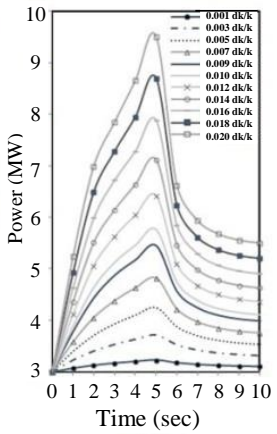

(c)
Fig. 2. Power profiles for MOC with increase of reactivity for different insertion durations of reactivity which are (a) $0.1 \mathrm{~s} \mathrm{(b)} 1 \mathrm{~s}$ and (c) $5 \mathrm{~s}$.

Table 2. Comparison of reactor parameters obtained from steady state analyses.

\begin{tabular}{ccccccc}
\hline Parameters for & \multicolumn{2}{c}{ BOC } & \multicolumn{2}{c}{ MOC } & \multicolumn{2}{c}{ EOC } \\
\cline { 2 - 7 } Temperature [ $^{0} \mathrm{C}$ ] & EUREKA & COOLOD & EUREKA & COOLOD EUREKA & COOLOD \\
\hline Fuel Meat & 703.16 & 703.30 & 697.31 & 696.61 & 695.79 & 695.64 \\
Cladding & 136.75 & 133.68 & 136.28 & 133.37 & 136.15 & 133.04 \\
Bulk Coolant & 46.74 & 44.27 & 46.67 & 44.24 & 46.66 & 44.20 \\
\hline
\end{tabular}

Peak values of power with its attaining time are summarized in Table 3 for all three burn states for each reactivity with each insertion duration. It is obvious from the table that the increase of reactor core power depends not only on amount of reactivity but also on its duration of insertion. From the concern of delayed neutron fraction of 0.007 for TRIGA [10], for the inserted reactivity less than 0.007 , the increase in power for reactivity of 0.001 to $0.005 \mathrm{dk} / \mathrm{k}$ is relatively slow. Reactor period to this extent of external reactivity is characterized by delayed neutrons and feedback mechanisms. But, from and beyond reactivity of $0.007 \mathrm{dk} / \mathrm{k}$, the power increase is faster which could be result of prompt critical condition of reactor, $\rho=\beta$. For all three burn steps, a rapid increase in power beyond reactivity of $0.007 \mathrm{dk} / \mathrm{k}$ is noticed for insertion duration of $0.1 \mathrm{~s}$. This insertion duration of $0.1 \mathrm{~s}$, is relatively too fast than the other two and for this duration unlikely there is some misleading results of reactor core power for the case of BOC. 
For this very fast duration, it is seen from Table 3 that magnitude of power obtained for $\mathrm{BOC}$ is relatively smaller than that of MOC and EOC which is not expected. While for other insertion durations, a decrease of power from BOC to EOC is noticed which is expected. Again, Table 3 shows although core power increases with the increase of reactivity for all three burn steps for all three insertion durations, but for insertion duration $0.1 \mathrm{~s}$, particularly for BOC, the calculated power takes lower values at the largest reactivity of $0.02 \mathrm{dk} / \mathrm{k}$ which is not expected. This kind of inconsistency arises for BOC due to transient with $0.1 \mathrm{~s}$ insertion duration whether having any impacts in fuel clad temperature transient has now been taken into discussion below.

Table 3. Peak power variation for all ranges and insertion durations of reactivity at three steps of core burnt.

\begin{tabular}{|c|c|c|c|c|c|c|c|c|c|}
\hline \multirow{3}{*}{$\mathrm{dk} / \mathrm{k}$} & \multicolumn{3}{|c|}{ BOC } & \multicolumn{3}{|c|}{ MOC } & \multicolumn{3}{|c|}{ EOC } \\
\hline & \multicolumn{9}{|c|}{ Reactivity Insertion Time } \\
\hline & $0.1 \mathrm{~s}$ & $1 \mathrm{~s}$ & $5 \mathrm{~s}$ & $0.1 \mathrm{~s}$ & $1 \mathrm{~s}$ & $5 \mathrm{~s}$ & $0.1 \mathrm{~s}$ & $1 \mathrm{~s}$ & $5 s$ \\
\hline 0.001 & $\begin{array}{c}3.46 \\
(0.14)^{*}\end{array}$ & $\begin{array}{l}3.39 \\
\text { (1) }\end{array}$ & $\begin{array}{l}3.22 \\
(5)\end{array}$ & $\begin{array}{c}3.46 \\
(0.13)\end{array}$ & $\begin{array}{l}3.39 \\
\text { (1) }\end{array}$ & $\begin{array}{l}3.22 \\
(5)\end{array}$ & $\begin{array}{c}3.46 \\
(0.13)\end{array}$ & $\begin{array}{l}3.39 \\
(1)\end{array}$ & $\begin{array}{c}3.22 \\
(5)\end{array}$ \\
\hline 0.003 & 5.01 & 4.49 & 3.71 & 5.01 & 4.48 & 3.70 & 5.02 & 4.49 & 3.70 \\
\hline 0.005 & $\begin{array}{c}(0.14) \\
8.84\end{array}$ & $\begin{array}{l}(1) \\
6.14\end{array}$ & $\begin{array}{c}(5) \\
4.25\end{array}$ & $\begin{array}{l}(0.13) \\
8.92\end{array}$ & $\begin{array}{l}(1) \\
6.13\end{array}$ & $\begin{array}{c}(5) \\
4.23\end{array}$ & $\begin{array}{l}(0.13) \\
8.92\end{array}$ & $\begin{array}{l}(1) \\
6.13\end{array}$ & $\begin{array}{c}(5) \\
4.23\end{array}$ \\
\hline & $(0.14)$ & (1) & (5) & $(0.14)$ & (1) & (5) & $(0.14)$ & (1) & (5) \\
\hline 0.007 & 22.65 & 8.49 & 4.81 & 23.97 & 8.47 & 4.81 & 23.96 & 8.47 & 4.81 \\
\hline & $(0.14)$ & (1) & (5) & $(0.13)$ & (1) & (5) & $(0.13)$ & (1) & (5) \\
\hline 0.009 & 77.16 & 11.11 & 5.44 & 88.43 & 11.08 & 5.44 & 88.30 & 11.09 & 5.44 \\
\hline 0.010 & $\begin{array}{l}(0.13 \mathrm{~s}) \\
13411\end{array}$ & $\begin{array}{l}\text { (1) } \\
1233\end{array}$ & $\begin{array}{l}(5) \\
576\end{array}$ & $\begin{array}{l}(0.13) \\
16419\end{array}$ & (1) & (5) & $(0.13)$ & (1) & (5) \\
\hline & $\begin{array}{l}134.11 \\
(0.13)\end{array}$ & $\begin{array}{l}12.33 \\
(1)\end{array}$ & $\begin{array}{l}3.10 \\
(5)\end{array}$ & $\begin{array}{l}104.19 \\
(0.12)\end{array}$ & (1) & (5) & $\begin{array}{l}103.80 \\
(0.12)\end{array}-3$ & $(1)$ & (5) \\
\hline 0.012 & 280.96 & 14.71 & 6.42 & 375.84 & 14.69 & 6.41 & 375.50 & 14.66 & 6.41 \\
\hline & $(0.10)$ & & & $(0.11)$ & (1) & (5) & $(0.11)$ & & (5) \\
\hline 0.014 & 481.16 & 16.95 & 7.14 & 639.60 & 16.89 & 7.11 & 640.39 & 16.88 & 7.11 \\
\hline & $(0.09)$ & (1) & (5) & $(0.10)$ & (1) & (5) & $(0.10)$ & (1) & (5) \\
\hline 0.016 & 753.31 & 19.30 & 7.89 & 667.81 & 19.21 & 7.88 & 670.28 & 19.23 & 7.88 \\
\hline 0018 & $(0.09)$ & (1) & (5) & $(0.09)$ & (1) & (5) & $(0.09)$ & (1) & (5) \\
\hline & $\begin{array}{c}982.40 \\
(0.08)\end{array}$ & $\begin{array}{c}22.03 \\
\text { (1) }\end{array}$ & $\begin{array}{l}8.69 \\
(5)\end{array}$ & $\begin{array}{c}838.85 \\
(0.09)\end{array}$ & $\begin{array}{c}21.95 \\
\text { (1) }\end{array}$ & $\begin{array}{l}8.69 \\
(5)\end{array}$ & $\begin{array}{c}822.75 \\
(0.09)\end{array}$ & $\begin{array}{c}21.90 \\
(1)\end{array}$ & $\begin{array}{l}8.08 \\
(5)\end{array}$ \\
\hline 0.020 & 890.47 & 24.86 & 9.53 & 1232.61 & 24.73 & 9.50 & 1237.55 & 24.72 & 9.51 \\
\hline & $(0.08)$ & (1) & (5) & $(0.08)$ & (1) & (5) & $(0.08)$ & (1) & (5) \\
\hline
\end{tabular}

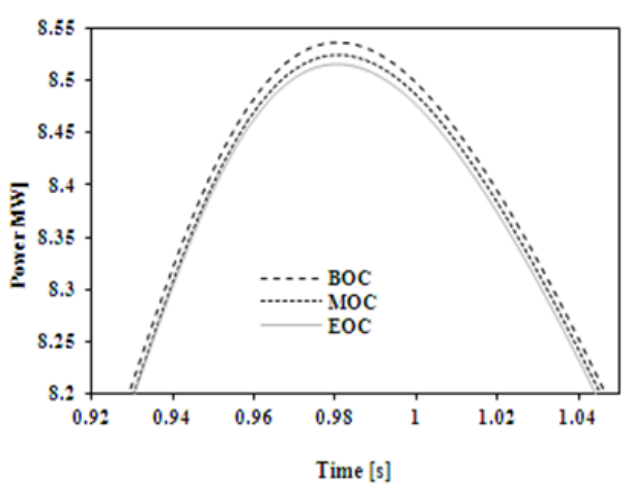

Fig. 3. Time function of power with the progress of core burnt for reactivity of $0.007 \mathrm{dk} / \mathrm{k}$ with insertion duration $1 \mathrm{~s}$.

\section{Transient of fuel clad tempera ture}

Although the increase in reactor power will increase the temperatures of fuel meat, cladding and coolant; however, only the fuel clad temperature is being considered here in terms of severity of clad melting.

Table 4 has provided increase of clad temperature with the increase of reactivity for different durations of insertion for three burnt steps of reactor. It is seen from this Table that for $0.1 \mathrm{~s}$ of insertion, clad temperature remains within its design limit, $500{ }^{\circ} \mathrm{C}$ until $0.014 \mathrm{dk} / \mathrm{k}$ reactivity for all three burnt steps. Similarly, no clad failure has been noticed until $0.018 \mathrm{dk} / \mathrm{k}$ reactivity for BOC with both $1 \mathrm{~s}$ and $5 \mathrm{~s}$ but for MOC and EOC only with $1 \mathrm{~s}$ of insertion duration. For $5 \mathrm{~s}$ insertion duration, MOC and EOC can retain clad within its design temperature until $0.020 \mathrm{dk} / \mathrm{k}$ reactivity. It is observed from the table that time to achieve the clad temperature to its maximum value decreases with the increase of reactivity. However, at the limit value of reactivity clad temperature observed to take relatively longer time to attain to its limit values which is due to balancing of positive and dopplers negative reactivity. Figure 4 presents clad temperature profiles for all ranges of reactivity for BOC which shows how clad temperature takes time to stand in its safety side for $0.014 \mathrm{dk} / \mathrm{k}$ reactivity with $0.1 \mathrm{~s}$ duration and for $0.018 \mathrm{dk} / \mathrm{k}$ reactivity with $1 \mathrm{~s}$.

Table 4. Peak clad temperature variation for all ranges and insertion durations of reactivity at three steps of core burnt.

\begin{tabular}{|c|c|c|c|c|c|c|c|c|c|}
\hline \multirow{3}{*}{$\mathrm{dk} / \mathbf{k}$} & \multicolumn{3}{|c|}{$\mathrm{BOC}$} & \multicolumn{3}{|c|}{ MOC } & \multicolumn{3}{|c|}{ EOC } \\
\hline & & & & \multicolumn{3}{|c|}{ Reactivity Insertion Time } & & & \\
\hline & $0.1 \mathrm{~s}$ & $1 \mathrm{~s}$ & $5 \mathrm{~s}$ & $0.1 \mathrm{~s}$ & 1s & $5 \mathrm{~s}$ & $0.1 \mathrm{~s}$ & $1 \mathrm{~s}$ & $5 \mathrm{~s}$ \\
\hline 0.001 & 139.17 & 139.16 & 139.13 & 137.94 & 137.93 & 137.90 & 137.82 & 137.81 & 137.78 \\
\hline & $(4)^{*}$ & (4.4) & (7.6) & (3.8) & (4.4) & (7.6) & (4) & $(4.6)$ & (7.6) \\
\hline 0.003 & 142.43 & 142.41 & 142.24 & 141.21 & 141.19 & 141.03 & 141.09 & 141.08 & 140.91 \\
\hline 0.005 & $\begin{array}{l}\text { (3) } \\
145.75\end{array}$ & $\begin{array}{l}\text { (3.6) } \\
145.69\end{array}$ & $\begin{array}{l}(7.2) \\
145.29\end{array}$ & $\begin{array}{c}\text { (3.2) } \\
144.54\end{array}$ & $\begin{array}{c}(3.8) \\
144.47\end{array}$ & $\begin{array}{c}(7.2) \\
144.06\end{array}$ & $\begin{array}{c}(3.2) \\
144.42\end{array}$ & $\begin{array}{c}(3.8) \\
144.36\end{array}$ & $\begin{array}{c}(7.2) \\
143.94\end{array}$ \\
\hline 0.007 & $\begin{array}{l}(2.2) \\
14914\end{array}$ & $\begin{array}{l}(3.0) \\
14897\end{array}$ & $\begin{array}{l}(6.8) \\
14829\end{array}$ & $\begin{array}{c}(2.4) \\
14791\end{array}$ & $\begin{array}{c}(3.0) \\
147775\end{array}$ & $\begin{array}{c}(6.8) \\
14709\end{array}$ & $\begin{array}{r}(2.4) \\
14779\end{array}$ & $\begin{array}{c}(3.0) \\
147.63\end{array}$ & $\begin{array}{c}(6.8) \\
14696\end{array}$ \\
\hline & & (2.9) & (6.4) & (1.6) & $(2.6)$ & (6.2) & (1.6) & (2.6) & $\begin{array}{c}14.90 \\
(6.6)\end{array}$ \\
\hline 0.009 & 153.50 & 152.27 & 151.26 & 152.21 & 151.06 & 150.06 & 152.09 & 150.94 & 149.93 \\
\hline & $(0.33)$ & $(2.2)$ & $(6.2)$ & $(0.32)$ & $(2.2)$ & ${ }_{15.2)}^{(6.2)}$ & $(0.32)$ & (2.2) & (6.2) \\
\hline 0.010 & 157.63 & 153.91 & 152.70 & 156.32 & 152.69 & 151.50 & 156.21 & 152.59 & 151.38 \\
\hline 0012 & $(0.29)$ & $\begin{array}{l}(2.0) \\
15720\end{array}-100$ & $\begin{array}{l}(6.0) \\
1553\end{array}$ & $\begin{array}{l}(0.26) \\
16862\end{array}$ & $\begin{array}{l}(1.8) \\
155.93\end{array}$ & $\begin{array}{c}(6.2) \\
154.32\end{array}$ & $\begin{array}{l}(0.26) \\
16844\end{array}$ & $\begin{array}{l}(2.0) \\
15580\end{array}$ & $\begin{array}{c}(6.2) \\
154.20\end{array}$ \\
\hline & $(0.28)$ & (1.6) & $(6.0)$ & $(0.25)$ & (1.6) & (6.2) & $(0.25)$ & (1.8) & (6.2) \\
\hline 0.014 & 237.37 & 160.47 & 158.35 & 209.44 & 159.16 & 157.10 & 208.47 & 159.03 & 156.98 \\
\hline & $(0.9)$ & (1.4) & $(5.8)$ & $(0.38)$ & (1.6) & $(6.0)$ & $(0.37)$ & (1.6) & $(6.0)$ \\
\hline 0.016 & & 164.78 & 161.13 & 4322.5 & 162.39 & 159.89 & 4312.85 & 162.26 & 159.76 \\
\hline 0.018 & ${ }_{41193}^{(80)}-2-3$ & (3.6) & (6.0) & ${ }_{4109}^{(80)}$ & $\begin{array}{l}(1.4) \\
179.40\end{array}$ & $\begin{array}{c}(5.8) \\
16261\end{array}$ & $\begin{array}{c}(1.2) \\
42458\end{array}$ & $\begin{array}{c}(1.4) \\
078.07\end{array}$ & $\begin{array}{c}(5.8) \\
16249\end{array}$ \\
\hline & & & & & & & $\begin{array}{c}42+50 \\
(80)\end{array}$ & (2.0) & $\begin{array}{l}10.49 \\
(5.8)\end{array}$ \\
\hline 0.020 & $\begin{array}{l}4253.2 \\
(80)\end{array}$ & $\begin{array}{l}47666.1 \\
(80)\end{array}$ & $\begin{array}{l}4496.7 \\
(80)\end{array}$ & $\begin{array}{c}4256.2 \\
(80)\end{array}$ & $\begin{array}{c}4648.1 \\
(80)\end{array}$ & $\begin{array}{c}184.73 \\
(7.9)\end{array}$ & $\begin{array}{c}4247.6 \\
(80)\end{array}$ & $\begin{array}{c}4635.1 \\
(80)\end{array}$ & $\begin{array}{c}182.28 \\
(7.2)\end{array}$ \\
\hline
\end{tabular}

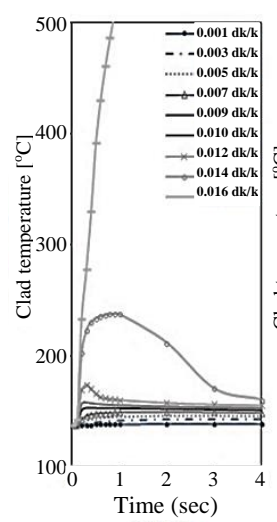

(a)

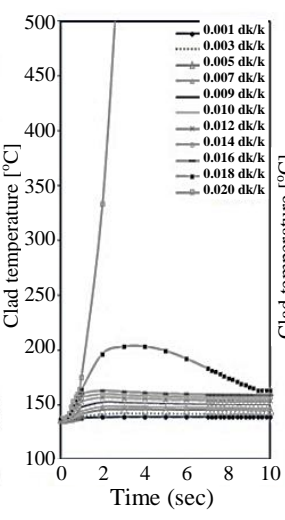

(b)

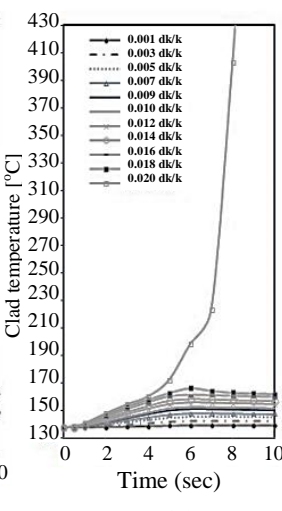

(c)
Fig. 4. Clad temperature profiles for BOC with increase of reactivity for different insertion durations of reactivity which are (a) $0.1 \mathrm{~s} \mathrm{(b)} 1 \mathrm{~s}$ and (c) $5 \mathrm{~s}$

Variations of clad temperatures with variation of dopplers reactivity have been discussed more elaborately in Fig. 5 for MOC considering 
reactivity insertion duration of $1 \mathrm{~s}$. Figure 5a shows the increase of dopplers negative reactivity with the increase of positively inserted reactivity. Figure $5 \mathrm{~b}$ to Fig. 5d illustrate how dopplers reactivity suppresses positive reactivity to keep clad temperature safe. Figure $5 \mathrm{~b}$ states clad temperature while attains maximum value of $162.39^{\circ}$ at $1.4 \mathrm{~s}$ for $0.016 \mathrm{dk} / \mathrm{k}$ reactivity, dopplers reactivity found to take its stable value of $1.4 \% \mathrm{dk} / \mathrm{k}$ at $4 \mathrm{~s}$. For increasing reactivity to $0.018 \mathrm{dk} / \mathrm{k}$, Fig. $5 \mathrm{c}$ shows while clad temperature reaches maximum at $2.4 \mathrm{~s}$, dopplers reactivity found to become closer to its stable value of about $1.6 \% \mathrm{dk} / \mathrm{k}$. In Figure $5 \mathrm{~d}$, for reactivity of $0.020 \mathrm{dk} / \mathrm{k}$, clad temperature shows to exceed its design limit. Doppler reactivity, in contrast, found to remain in its stable values from 1.73 to $1.715 \mathrm{dk} / \mathrm{k}$ from $4.6 \mathrm{~s}$ of transient. This indicates dopplers reactivity unable to keep clad temperature safe at this large extent of reactivity. Hence, core safety depends on how far Doppler reactivity could compensate positively induced reactivity.

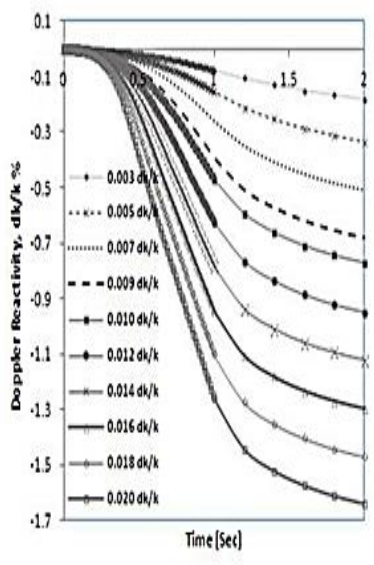

(a)

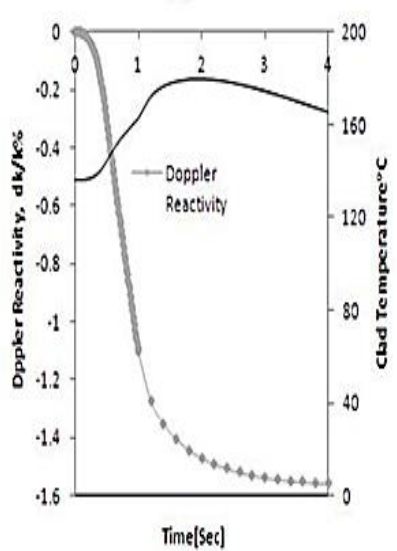

(c)

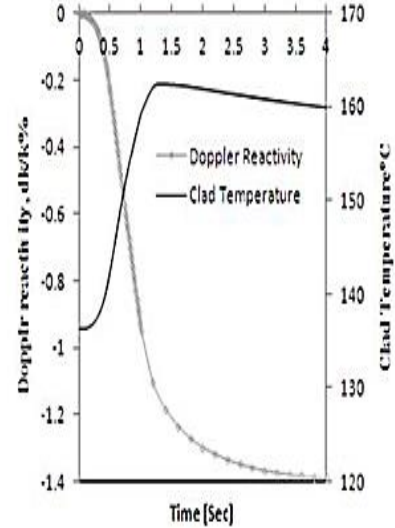

(b)

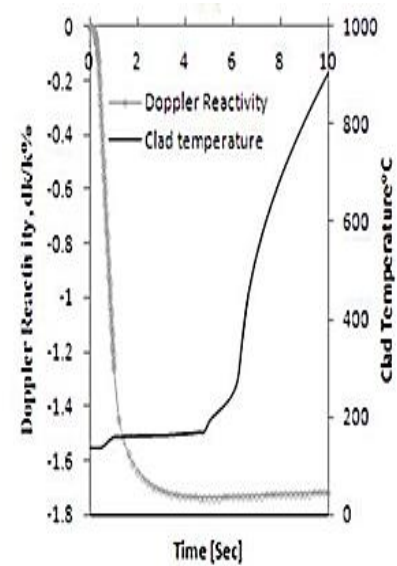

(d) 1
Fig. 5. Response of dopplers reactivity (a) with increase of positively inserted reactivity (b) with transient of clad temperature for $0.016 \mathrm{dk} / \mathrm{k}$ reactivity (c) with transient of clad temperature for $0.018 \mathrm{dk} / \mathrm{k}$ reactivity and (d) with transient of clad temperature for $0.020 \mathrm{dk} / \mathrm{k}$ reactivity for MOC with $1 \mathrm{~s}$ insertion duration.
Table 4 also shows for each duration of insertions, for a fixed amount of reactivity, fuel clad temperature decreases with the increase of core burnt, which is expected. This behavior of clad temperature, in fact, noticed during steady state analysis [9] which illustrated that decrease of total power peaking factors of the reactor turns fuel, clad and coolant temperature to decrease with the increase of core burn. Figure 6 presents profile of clad temperature for three different states of core burnt for reactivity of $0.007 \mathrm{dk} / \mathrm{k}$ reactivity with insertion duration of $1 \mathrm{~s}$. This figure shows temperature profile for BOC stands relatively higher in position in compare to that of MOC and EOC where MOC lies slightly above from EOC. The possible cause may be effects of other parameters say, feedback reactivity or others with the progress of core burnt.

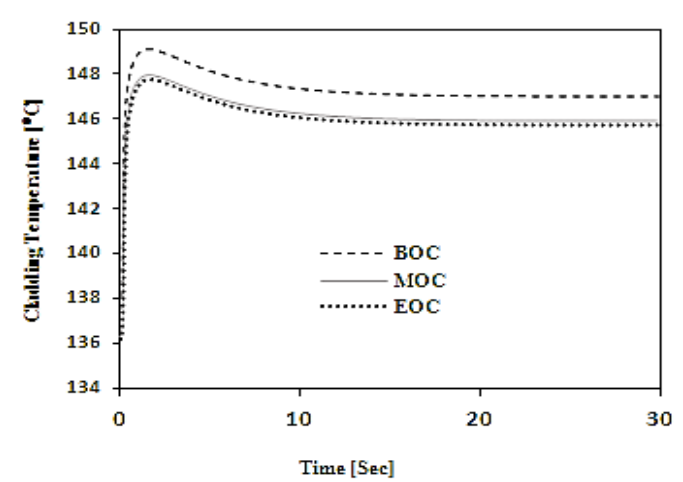

Fig. 6. Time function of clad temperature with the progress of core burnt for reactivity of $0.007 \mathrm{dk} / \mathrm{k}$ with insertion duration $1 \mathrm{~s}$

\section{CONCLUSION}

The present study reported that during progress of core burnt of TRIGA Mark-II reactor, negative feedback reactivity plays significant roles in controlling core power and clad temperature to protect reactor from any damage during reactivity initiated transient. This study has evaluated maximum inserted reactivity at each burn step and found for all three steps of core burnt there is no failure of fuel clad until $0.014 \mathrm{dk} / \mathrm{k}$ reactivity while insertion duration is $0.1 \mathrm{~s}$. However, this limit of reactivity to retain clad temperature within its design limit is found increasing with the progress of core burnt. It is observed that maximum of both core power and clad temperature decreases with the progress of core burnt for each amount and insertion duration of reactivity. However, an exception is noticed for core power response while inserted reactivity is very fast, as it is $0.1 \mathrm{~s}$ insertion duration in the present study. This could be due to limitations of EUREKA code to comply with such fast transient with fresh core. More efforts need to be paid in this regard in future. 
The authors interests at present to extend the research considering further burn states of TRIGA reactor. In addition, with the variation of duration of inserted reactivity, how feedback reactivity including coolant temperature and density feedback, also other kinetic parameters, say, prompt neutron generation time, effective delayed neutron fraction influence on the reactor safety are also of concern of the research.

\section{ACKNOWLEDGMENT}

The authors would like to acknowledge Dr. Masanori Kaminaga of Japan Atomic Energy Research Institute (JAERI) for his comments on the TRIGA modeling. The authors are also thankful to the members of RPED for their cooperation.

\section{REFERENCES}

1. M.Q. Huda, S.I. Bhuiyan, T. Obara, Ann. of Nucl. Energy. 35 (2008) 141.

2. M. Rahman, M.S. Mahmood, M.T. Chowdhury et al., Sharing Neutronics Calculation Technique for Core Management and Utilization of Research Reactors, JAEAReview 2010-025 (2010) 10.
3. M.S. Mahmood, Z.I. Lyric, M.A. Motalab et al,. Individual fuel element burnup of BAEC TRIGA core, Technical Report, INST-RPEDRARD-01/009 (2012).

4. M. Asaduzzaman, S.M.A. Islam, M.J.H Khan et al., IJRASET 4 (2016) 473.

5. C. Housiadas, Ann. of Nucl. Energy. 27 (2000) 1683.

6. N.H. Badrun, M.H. Altaf, M.J.H. Khan et al., Ann. of Nucl. Energy. 41 (2012) 40.

7. N.H. Badrun, M.H. Altaf and M.T. Chowdhury, Ann. of. Nucl. Energy. 85 (2015) 394.

8. M.H. Altaf, S.M Tazul Islam and N.H. Badrun, Atom Indonesia 43 (2017) 69.

9. M.H. Altaf and N.H. Badrun, Atom Indonesia 40 (2014) 107.

10. Anonymous, Safety Analysis Report, General Atomic, E-117-990 (1991).

11. M. Kaminaga, COOLOD-N2 Code, Japan Atomic Energy Research Institute, Japan (1994).

12. Anonymous, A Strain based Clad Failure Criterion for Reactivity Initiated Accidents in Light Water Reactors, SKI Report 32 (2004). 